\title{
O método do jornalista
}

Liriam Sponholz

Jornalista, mestra em História pela Universidade Federal do Paraná e doutora

em Comunicação pela Universidade de Leipzig.

E-mail: l_sponholz@hotmail.com

Resumo: Jornalistas utilizam um método quando produzem suas notícias e reportagens? Como é este método? Neste artigo, pretende-se responder a estas perguntas através de um estudo empírico com jornalistas brasileiros e alemães. Os resultados mostram não só como jornalistas procuram conhecer a realidade, como também os problemas enfrentados ao tentarem alcançar este objetivo.

Palavras-chave: jornalismo, método, reportagem, notícias, imprensa.
Abstract: Is there a method to journalism? What does this method entail? The article addresses these questions on the basis of an empirical study of Brazilian and German journalists. The results indicate that journalists follow a certain method, which can thus be learned. At the same time, this method reflects the difficulties encountered by journalists in their search for reality.

Keywords: journalism, method, reporting, news, press.

O que faz de um jornalista um bom profissional? Trata-se de uma questão de vocação ou isto pode ser ensinado? A discussão sobre a possibilidade de aprender-se jornalismo leva a uma outra, a existência de um método jornalístico. Se este não existe ${ }^{1}$, não há alternativa para aqueles que querem ser jornalistas a não ser jogar-se no rio e sair nadando.

Neste artigo, pretende-se buscar uma resposta a estas perguntas: o jornalismo tem um método? Caso tenha, como é este método? Quais são as estratégias dos jornalistas para conhecer a realidade?

Por método entende-se aqui uma série de ações ou decisões planejadas e adotadas conscientemente para alcançar determinado objetivo ${ }^{2}$. Estas ações não são tomadas automaticamente (como, por exemplo, aquelas utilizadas para abrir uma porta), pois exigem o uso de inteligência (são conscientes) e representam uma escolha entre possibilidades diferentes ${ }^{3}$.

Através de certo método, estabelece-se contato com o mundo exterior, ou seja, confronta-se o que já se sabe e/ou o que se pressupõe com a realidade, ou o mundo exterior. No caso do jornalismo, pode-se dizer que um método é utilizado quando as ações ou decisões dos jornalistas seguem uma linha de raciocínio e são planejadas para alcançar determinado objetivo, o que significa que são tomadas de forma consciente.

Recebido: 28/11/2006 Aprovado: 06/11/2007

1. Ver: MEDITSCH, Eduardo. Método científico e método jornalístico. Revista Brasileira de Comunicação, n. 60, p. 55-61, 1989 .

2. MEHRTENS, A. Methode/Methodologie (Método/Metodologia). In: SANDKÜHLER, H. J. Enzyklopädie Philosophie. Hamburg: Felix Meiner 1999.

3. HEINRICH, R. Einführung in die Philosophie der Renaissance (Introdução à Filosofia da Renascença). 1998. Disponível em: <http://sammelpunkt.philo.at:8080/ archive/00000037/01/ book1.htm>. Acesso em 10 mar. 2008. 
comunicação \& educação • Ano XIII • Número 2 - maio/ago 2008

\section{MÉTODO DA PESQUISA}

Para avaliar se jornalistas utilizam um método na produção de notícias e reportagens, foram entrevistados 40 repórteres, 20 brasileiros e, os demais, alemães. Eles trabalham nas editorias local, política e de economia dos jornais Die Welt (Hamburgo), Sueddeutsche Zeitung (Munique), Frankfurter Allgemeine Zeitung (Frankfurt), Frankfurt Rundschau (Frankfurt), Leipziger Volkszeitung (Leipzig), Rheinischer Post (Düsseldorf), Der Tagesspiegel (Berlim) e Westdeutsche Allgemeine Zeitung (Essen), na Alemanha, e nos jornais Folha de S. Paulo, O Estado de S. Paulo, Jornal do Brasil, O Globo, Gazeta do Povo, Zero Hora, Correio Braziliense e Estado de Minas, no Brasil. Os jornalistas alemães foram entrevistados por telefone entre maio e junho de 2004, e os brasileiros em julho do mesmo ano.

Simulando a situação na qual o jornalista produz uma notícia ou uma reportagem a partir de um press release, foram enviados textos com histórias baseadas em notícias dos jornais de ambos os países antes da entrevista. Estas foram apresentadas do ponto de vista de uma fonte. No final de cada texto constava o telefone de um assessor de imprensa à disposição para prestar informações. Para cada editoria e tipo de jornal (regional ou nacional), formulou-se uma história diferente. Os entrevistados sabiam que se tratava de textos fictícios.

Os temas escolhidos são polêmicos e exigiriam uma investigação jornalística. $\mathrm{Na}$ Alemanha, as narrativas tratavam de repatriamento de candidatos a asilo político, um conflito com uma comunidade judaica, e a demissão em massa em uma grande indústria alemã. No Brasil, os temas abordavam a intervenção do Exército no combate à violência nas cidades, um conflito com o Movimento Sem-Terra e a transferência de fábricas de uma indústria multinacional para o exterior.

Durante a entrevista, os jornalistas responderam como produziriam uma matéria a partir destas histórias. Assim, através desta pesquisa pôde-se levantar os quadros escolhidos, as fontes que seriam ouvidas, as informações que gostariam de obter de cada uma delas e as hipóteses dos jornalistas sobre o tema.

Estes dados foram codificados com um instrumentário próprio e interpretados com instrumentos estatísticos. Os dados se baseiam no número de jornalistas, de problemas, ou em quadros formulados por estes, além de fontes e de hipóteses.

Quanto mais o índice de correlação entre dois fatores (Cramer-V) aproximarse de 1 (um), mais forte será a associação entre eles. O valor de significância funciona aqui como um instrumento de ajuda para avaliar se é razoável falar de uma força de associação entre os fatores. Se o valor de significância for menor ou até 0,1 , pode-se dizer que a correlação entre os fatores faz sentido. Como o universo de pesquisa não foi escolhido aleatoriamente e, portanto, não é representativo, os resultados mostram determinado recorte da realidade sobre os métodos jornalísticos, sem necessariamente refletir o todo. 


\section{RESULTADOS}

Dos 40 jornalistas entrevistados, 38 declararam que havia algo na história que exigiria um esclarecimento ou uma investigação mais aprofundada.

\section{DEFININDO O PROBLEMA}

A maioria dos entrevistados definiu o problema ou a pergunta central à qual gostaria de responder com a sua investigação. Em outras palavras, eles definiram os objetivos que gostariam de alcançar.

Quando definiram o que investigar, ou seja, como enquadrariam os temas, 31 entrevistados formularam mais do que um problema. Isto significa que trabalhariam com mais de uma tentativa de lead. Lead é o primeiro parágrafo de uma notícia, que deve resumir o aspecto mais importante de um tema ao responder às questões sobre o quê, quem, onde, quando, como e por quê.

Os quadros propostos na entrevista ofereciam a possibilidade de escolha nas seguintes categorias: temáticos, de acontecimento ou de conflito. No primeiro caso, o entrevistado se concentraria no tema que envolve a história. Nos quadros de acontecimento, ele se ateria a um recorte temporal e espacial. Nos quadros de conflito, o jornalista se limitaria a ouvir os dois lados da polêmica.

Tome-se como exemplo o caso da narrativa fictícia PM intensifica desarmamento na região metropolitana, que trata de uma reunião entre representantes da Secretaria de Segurança Pública e do Sindicato dos Trabalhadores no Transporte Coletivo para discutir medidas contra os assaltos em ônibus nas linhas da região metropolitana. O sindicato propõe a colocação de um policial em cada ponto de ônibus, enquanto a polícia aposta na intensificação do desarmamento nas regiões afetadas. Se o entrevistado se concentrasse no problema da segurança pública na região metropolitana, então ele escolheria um quadro temático. Caso preferisse se ater à reunião e aos seus resultados, o seu trabalho se basearia em um quadro de acontecimento. No caso de um quadro de conflito, o jornalista se limitaria a ouvir a opinião do representante do sindicato e a do representante da Secretaria sobre o encontro e sobre as soluções apresentadas.

No grupo analisado, a metade dos quadros escolhidos foi de acontecimento. Um terço destes representam quadros temáticos e $17 \%$, quadros de conflitos. Ou seja, os jornalistas se concentrariam, via de regra, no encontro, e não no problema da segurança pública. Isto revela que o quê e como os jornalistas investigam não se baseiam somente nos seus interesses pessoais, mas é determinado basicamente por dois fatores: as rotinas produtivas e a relevância (valor-notícia) do tema ${ }^{4}$. Quanto às rotinas produtivas, o jornalista escolhe um aspecto do tema que pode ser investigado dentro das condições que se dispõe para isso, como, por exemplo, tempo. Este é o caso dos quadros de acontecimento.

Se escolher um quadro temático, ele terá que ouvir um número e uma diversidade maior de fontes. Se optar pelo problema da segurança púbica, precisará entrevistar tanto os responsáveis quanto as pessoas afetadas
4. TRAVANCAS, I. S. O mundo dos jornalistas. São Paulo: Summus, 1993; PEREIRA JUNIOR, A. E. V. Decidindo o que é notícia: os bastidores do telejornalismo. 3. ed. Porto Alegre: Edipucrs, 2003. 
pelo problema, ou seja, tanto o comandante da polícia quanto as vítimas de assalto, motoristas de ônibus, moradores. Parte destas fontes exige um esforço de investigação maior. Ao contrário do presidente do sindicato ou do comandante da polícia, as vítimas de assalto, motoristas de ônibus e moradores não podem ser alcançados através de assessoria de imprensa. Se o jornalista se concentrar somente na reunião, basta ouvir os que participaram do encontro, ou seja, os representantes do sindicato e os da Secretaria de Segurança Pública.

\section{ESCOLHENDO AS FONTES}

Os entrevistados escolheriam as suas fontes de acordo com a questão a ser investigada. Ou seja, eles não só estabeleceriam um ou mais objetivos, como também se orientariam nestes para selecionar suas fontes. Informantes escolhidos sem considerar o objetivo estabelecido representam uma exceção: só $5 \%$ das pessoas que os jornalistas entrevistariam não estão em correlação direta com a questão a ser investigada.

Os tipos de fontes a serem ouvidas variam de acordo com o enquadramento da história. Se o jornalista escolhesse um quadro de conflito, a maior parte das suas fontes seria do tipo afetado pelo problema, ou seja, as vítimas de assalto, o trabalhador em greve, o estrangeiro que solicitou asilo.

Se o jornalista preferisse um quadro de acontecimento, mais da metade das pessoas que ouviria seria de fontes oficiais. No caso do quadro temático, a divisão entre os diversos tipos é mais equilibrada. Isto mostra que o enquadramento de um tema é um fator decisivo na escolha das fontes.

Tabela 1 - Tipos de fonte por quadro (Número de fontes em \%)

\begin{tabular}{|c|c|c|c|c|}
\multicolumn{1}{c|}{} & $\begin{array}{c}\text { Quadro de } \\
\text { conflito }\end{array}$ & $\begin{array}{c}\text { Quadro de } \\
\text { acontecimento }\end{array}$ & $\begin{array}{c}\text { Quadro } \\
\text { temático }\end{array}$ & Total \\
\hline $\begin{array}{c}\text { Afetados pelo } \\
\text { problema }\end{array}$ & 35,7 & 20 & 34,5 & 26,8 \\
\hline Oficiais & 21,4 & 60 & 40 & 49 \\
\hline Expert & 7,1 & 10 & 16,4 & 14,8 \\
\hline Outros & 35,7 & 10 & 16,4 & 14,8 \\
\hline Cramer-V=0,214 & $\alpha=0,033$ & $\mathrm{~N}=149$ \\
\hline
\end{tabular}

A seleção das fontes não obedece somente ao quadro definido pelo jornalista, mas varia também de acordo com a editoria. Repórteres de economia ouviriam mais especialistas do que os demais, e os de política prefeririam fontes oficiais. As fontes afetadas por um problema seriam entrevistadas, sobretudo, por jornalistas da editoria local. 


\section{ENTREVISTANDO AS FONTES: LEVANTAMENTO E AVERIGUAÇÃO DOS FATOS}

Uma investigação jornalística exige o esclarecimento de uma situação em dois níveis. O primeiro, o nível factual, se restringe a o quê, quem, quando e onde. O segundo, o nível interpretativo, envolve as perguntas como e por quêt .

A maioria dos entrevistados investigaria ambos os níveis. Só seis dos 38 participantes iriam se ater a um dos níveis. Cinco deles iriam pesquisar somente o como e o por quê, ou seja, reduziriam a sua investigação a ouvir os dois lados envolvidos em uma polêmica.

O esclarecimento dos dois níveis requer fontes e um esforço de pesquisa diferentes. No nível factual (o quê, quem, onde e como), o levantamento das informações exige, sobretudo, entrevistas com fontes oficiais, como, por exemplo, o representante da Secretaria de Segurança Pública.

Informações em nível factual são mais difíceis de ser averiguadas com uma segunda fonte. Quem pode fornecer informações sobre o quê, quando e como a polícia fará, além do próprio representante da Secretaria? Assim, no caso das informações de nível factual, na maior parte dos casos, os jornalistas utilizariam simplesmente as informações contidas no press release, ou ouviriam as mesmas fontes citadas neste, em vez de averiguá-las com um outro informante.

\section{ENTREVISTANDO AS FONTES: FORMULAÇÃO DE HIPÓTESES}

As perguntas que um jornalista faria aos seus informantes seguem o problema formulado ou o quadro escolhido, mas contêm também as suspeitas, pressupostos ou idéias que ele tem sobre o tema.

Hipóteses jornalísticas podem ser de três tipos: a) descritivo ("O prefeito recebeu 300 mil dólares de uma empreiteira em sua conta pessoal”); b) evaluativo ("O prefeito é corrupto") e c) prescritiva ("O prefeito deveria renunciar") ${ }^{6}$.

Só hipóteses descritivas são empíricas e podem ser testadas intersubjetivamente. Se uma hipótese do tipo "o presidente é ruim" é correta ou não, isto depende exclusivamente de quem a formulou. Já no caso de frases do tipo "O atual presidente reduziu o investimento em educação em $30 \%$ durante o seu governo", pode-se dizer se ela é correta ou não, indiferentemente daquele que a formulou.

Só três jornalistas não formularam hipóteses. Isto não significa que eles não tenham uma opinião sobre o tema. Entretanto, não a utilizaram porque reduziriam sua investigação ao nível factual. Isto revela um outro aspecto do método jornalístico: os jornalistas só formulam hipóteses quando buscam respostas às perguntas como e por quê.

A maior parte das hipóteses que os entrevistados formularam $(67 \%)$ é descritiva, $25 \%$ é evaluativa e $9 \%$, prescritiva. Em todas as editorias, a maioria das hipóteses formuladas é descritiva, ou seja, pode ser comprovada ou refuta-
5. Ver: GUERRA, J. L. Ensaio sobre o Jornalismo: um contraponto ao ceticismo em relação à tese da mediação jornalística. Congresso da Associação dos Programas de Pós-Graduação em Comunicação-Compós, Porto Alegre. 2000.

6. STOCKING, S. H.; LAMARCA, N. How Journalists describe their stories: Hypotheses and Assumptions in Newsmaking (Como jornalistas descrevem suas histórias: hipóteses e pressupostos na produção de notícias). Journalism Quarterly, n. 67(2), p. 295-301, 1990. 
comunicação \& educação • Ano XIII • Número 2 • maio/ago 2008

da intersubjetivamente. No entanto, este percentual varia. No caso da editoria local, quatro de cada cinco hipóteses são descritivas. A maior parte de hipóteses evaluativas foi formulada pelos repórteres de política, enquanto hipóteses prescritivas são mais freqüentes na editoria de economia.

Gráfico 1 - Tipos de hipóteses por editoria (Número de hipóteses em \%)

\begin{tabular}{|c|c|c|c|c|c|}
\hline \multirow{2}{*}{ Editoria } & \multicolumn{5}{|c|}{ em $\%$} \\
\hline & Descritiva & Evaluativa & \multicolumn{3}{|c|}{ Prescritiva } \\
\hline Economia & \multicolumn{2}{|c|}{57,9} & 26,3 & \multicolumn{2}{|c|}{15,8} \\
\hline Política & \multicolumn{2}{|c|}{65,3} & \multicolumn{2}{|c|}{31,3} & 3 \\
\hline Local & \multicolumn{2}{|c|}{78,1} & \multicolumn{2}{|c|}{15,6} & 6,3 \\
\hline Cramer-V= & \multicolumn{2}{|l|}{$\alpha=0,012$} & \multicolumn{3}{|c|}{$N=207$} \\
\hline
\end{tabular}

Repórteres de política formularam hipóteses não-empíricas ao julgar os fatos pelos seus próprios valores. Neste caso, os entrevistados tentariam, por exemplo, verificar se um programa político poderia ser bem-sucedido. Mas quais são os critérios para definir o que significa ser bem-sucedido? Bem-sucedido para quem?

Os repórteres de economia entrevistados formularam hipóteses não-empíricas ao sugerir soluções para os problemas a serem noticiados. Isto acontece quando um repórter não só pergunta para um especialista o que deve ser feito, mas também propõe saídas para uma crise, e então questiona o que a fonte acha da proposta. Outra situação comum nesta editoria ocorre quando os jornalistas tentam fazer previsões.

O exemplo de Laura O., repórter de economia de um jornal brasileiro de circulação nacional, ilustra este procedimento. Ela recebeu a história Indústria automobilística XZ pode fechar fábricas no Brasil e quer verificar se a empresa não deveria esperar um pouco antes de transferir as suas fábricas para o exterior, "se, dada a situação dessa empresa, essa seria a decisão ideal, ou se ela deveria suportar esse momento para garantir mercado interno, suportando essa fase difícil até que a situação se equilibrasse".

\section{ENTREVISTANDO AS FONTES: LEVANTAMENTO DO NÍVEL INTERPRETATIVO}

O levantamento das informações do nível interpretativo, ou seja, de respostas às perguntas como e por quê, requer um outro tipo de fonte do que o nível factual. Enquanto neste caso o jornalista procura, sobretudo, fontes oficiais, o 


\section{método do jornalista - Liriam Sponholz}

nível interpretativo exige fontes parciais, ou seja, informantes que defendam determinada posição sobre o tema e especialistas.

Na maior parte dos casos, os entrevistados não só levantariam informações sobre como e por quê, como também o fariam com mais de uma fonte. Ou seja, eles ouviriam os dois lados de uma polêmica.

No entanto, como já foi analisado, isto só ocorreria com informações do nível interpretativo. Em outras palavras, se estes jornalistas recebessem um press release, eles procurariam as fontes citadas neste e as entrevistariam, mas não averiguariam as informações fornecidas sobre o quê, quem, quando e onde com uma segunda fonte. Sua investigação praticamente se resumiria a ouvir os dois lados.

\section{DIFERENÇAS ENTRE JORNALISTAS BRASILEIROS E ALEMÃES}

Praticamente não há diferença entre os métodos descritos pelos entrevistados de ambos os países. Uma correlação significativa da origem dos jornalistas só foi observada no caso dos quadros, dentro dos quais os entrevistados formularam os seus problemas ou as suas questões de investigação. Enquanto os jornalistas brasileiros preferiram quadros temáticos, seus colegas alemães optaram por quadros de acontecimento. Como quadros temáticos exigem mais fontes e um esforço de investigação maior, isto sugere uma maior disposição para investigar do jornalista brasileiro do que do seu colega alemão.

Deve-se, no entanto, lembrar que os resultados desta pesquisa refletem como os jornalistas pensam que devem fazer sua investigação e não como eles a realizam de fato. Por isso, é provável que a diferença entre ambos os grupos de jornalistas se deva àquilo que retratam como ideal, e não a como eles realmente agem. No Brasil, investigar é o primeiro mandamento no catálogo de um bom jornalista, enquanto na Alemanha os critérios de qualidade jornalística estão ancorados na tarefa de comentar.

\section{CONCLUSÕES}

Ao produzir uma notícia ou uma reportagem, jornalistas repetem um mesmo caminho inconscientemente, que é aprendido no processo de socialização nas redações e determinado pelas rotinas produtivas ${ }^{7}$. Ao mesmo tempo, os procedimentos de escolher o tema, enquadrá-lo, selecionar fontes, formular perguntas para estas exigem uma racionalidade mínima. Estes procedimentos incluem uma série de decisões que não são tomadas de forma obrigatória ou automática, como, por exemplo, enfiar a chave na fechadura para abrir a porta.

As decisões tomadas também não são arbitrárias, pois levam a determinado objetivo, o de procurar aquilo que se deseja saber. As fontes escolhidas precisam estar relacionadas com aquilo que o jornalista quer descobrir, ou seja, os infor-
7. BARROS FILHO, C. Reflexo de pauta: ética e habitus na produção da notícia. Contracampo, $n$ 7(2), p. 157-183, 2002. 
comunicação \& educação • Ano XIII • Número 2 - maio/ago 2008

mantes têm de ser adequados para fornecer as informações que ele necessita. Pode-se, portanto, afirmar que existe um método jornalístico a ser aprendido no dia-a-dia das redações, mas também antes de ser jogado no rio.

Ao mesmo tempo, a influência das rotinas produtivas faz com que muitas chances de aproximar-se da realidade sejam desperdiçadas. Quando jornalistas escolhem um quadro de acontecimento em vez de temático, problemas sociais passam a ser reduzidos a uma intriga entre políticos. A falta de averiguação das informações do nível factual com uma segunda fonte também é problemática.

O estudo destes métodos (escolhas racionais), bem como da sua relação com as rotinas produtivas (repetições inconscientes), mostra que aprender jornalismo antes de exercer a profissão é possível, mas este aprendizado não deve se reduzir a uma mera repetição do que é feito em uma redação.

\section{REFERÊNCIAS BIBLIOGRÁFICAS}

BARROS FILHO, C. Reflexo de pauta: ética e habitus na produção da notícia. Contracampo, n. 7(2), 2002.

GUERRA, J. L. Ensaio sobre o Jornalismo: um contraponto ao ceticismo em relação à tese da mediação jornalística. Congresso da Associação dos Programas de Pós-Graduação em Comunicação - Compós, Porto Alegre. 2000.

HEINRICH, R. Einführung in die Philosophie der Renaissance. 1998. Disponível em: <http://sammelpunkt.philo.at:8080/archive/00000037/01/book1. htm>. Acesso em 10 mar. 2008.

LASSWELL, H. A estrutura e a função da comunicação na sociedade. In: COHN, G. (Org.). Comunicação e indústria cultural. São Paulo: Cia. Editora Nacional, 1970.

MEDITSCH, Eduardo. Método científico e método jornalístico. Revista Brasileira de Comunicação, n. 60, 1989.

MEHRTENS, A. Methode/Methodologie. In: SANDKÜHLER, H. J. Enzyklopädie Philosophie. Hamburg: Felix Meiner, 1999.

PEREIRA JUNIOR, A. E. V. Decidindo o que é notícia: os bastidores do telejornalismo. 3. ed. Porto Alegre: Edipucrs, 2003.

STOCKING, S. H.; LAMARCA, N. How Journalists describe their stories: Hypotheses and Assumptions in Newsmaking. Journalism Quarterly, n. 67(2), 1990.

TRAVANCAS, I. S. O mundo dos jornalistas. São Paulo: Summus, 1993. 